\title{
Threshold Voltage Start-up Boost Converter for Sub-mA Applications
}

\author{
Ngok-Man Sze, Wing-Hung Ki and Chi-Ying Tsui \\ Department of Electronic and Computer Engineering \\ The Hong Kong University of Science and Technology \\ Hong Kong SAR, China \\ \{arsenic, eeki, eetsui\}@ece.ust.hk
}

\begin{abstract}
A threshold voltage start-up (TVS) scheme for a boost converter is presented. The TVS converter could start up at the average threshold voltage of the fabrication process, and converts a fluctuating (energy harvesting) input of $0.2 \mathrm{~V}$ to $0.9 \mathrm{~V}$ to a regulated output of $1.2 \mathrm{~V}$. It operates in discontinuous conduction mode with peak current control (and thus operates with pulse frequency modulation) to reduce switching loss at light loads. The converter was designed with an AMS $0.35 \mu \mathrm{m}$ CMOS process and measured $675 \mu \mathrm{m} \times 615 \mu \mathrm{m}$. The maximum efficiency is $83 \%$ at an output current of $1 \mathrm{~mA}$ with an input voltage of $0.9 \mathrm{~V}$.
\end{abstract}

Keywords: Boost converter, DC-DC converter, energy harvesting, PFM, start up

\section{Introduction}

Energy harvesting can be employed in many applications, and one of the applications is the wireless micro-sensor network [1] that consists of several to thousands of distributed nodes which sense and process data and pass the results to end-users. This application is useful for military target tracking, industrial monitoring and home environmental control, to name a few. Since there are too many sensing nodes in the network, it is impossible to replace batteries for these nodes regularly, and energy harvesting techniques with energy storage components could theoretically provide them with an infinite lifetime.

Some researchers assume a voltage source of at least $1 \mathrm{~V}$ is available for energy harvesting systems [2] [4]. However, some sources such as solar cells vary dramatically with a 24-hour solar cycle for outdoor applications [5]. The power profile of a solar cell is fluctuating and is different from a regular battery. Therefore, a special converter (Figure 1) for converting this fluctuating source to a regulated voltage is needed.

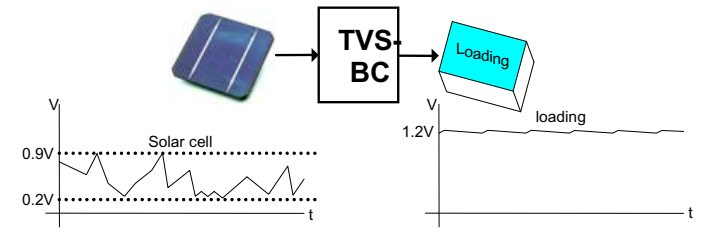

Figure 1: Operation of TVS boost converter

This research is in part supported by Research Grant Council under Grants 614506, 620305 and CERG 6311/04.

\section{Start-up mechanisms}

\subsection{Comparison of start-up schemes}

The start-up of a buck (step-down) switching converter poses no problem, as the functional blocks are driven by the input (or source) voltage $V_{s}$ which is the highest voltage of the system. For a boost converter, in order to drive the output switch (usually a PMOS transistor) effectively, the buffer has to be driven by the highest voltage of the converter, which is the output voltage $\mathrm{V}_{\mathrm{o}}$. However, at start-up, $\mathrm{V}_{\mathrm{o}}$ is zero and the buffer cannot even function. Therefore, special care has to be taken, but very few papers in the literature discussed the start-up circuitry for boost converters.

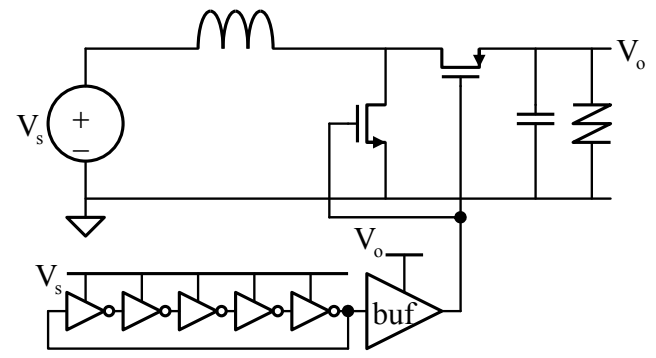

Figure 2: Conventional start-up scheme

One start-up mechanism of a boost converter was discussed in [6] (Fig. 2). It made use of a conventional ring oscillator with a conventional inverter driven by the supply voltage $\mathrm{V}_{\mathrm{s}}$. Therefore, the minimum start-up voltage $\mathrm{V}_{\text {st(min) }}$ has to be higher than the threshold voltages of the employed process to turn on and off the power transistors effectively. In fact, the converter used a $0.6 \mu \mathrm{m}$ CMOS process with $\mathrm{V}_{\text {tn }}=\left|\mathrm{V}_{\mathrm{tp}}\right|=\mathrm{V}_{\text {th(ave) }}=0.85 \mathrm{~V}$, and $\mathrm{V}_{\mathrm{st}(\min )}$ was demonstrated to be $1.18 \mathrm{~V}_{\mathrm{tn}}=1 \mathrm{~V}$. The ring oscillator 
generates a $50 \%$ duty cycle clock for the switches, and ideally, the converter could reach $2 \mathrm{~V}_{\mathrm{s}}$ if the inductor current is in continuous conduction mode (CCM). However, due to a low load current, the inductor current would operate in discontinuous conduction mode (DCM), and also due to losses, with $1 \mathrm{~V}$ for start-up, the unregulated output voltage thus achieved is $1.2 \mathrm{~V}_{\mathrm{st}(\min )}=1.2 \mathrm{~V}$. In [6], the power stage was driven by the output voltage $\mathrm{V}_{\mathrm{o}}$ directly to turn on the PMOS power transistor, and the output capacitor is charged to the input voltage prior to the start-up process. This charge up time is proportional to $\mathrm{V}_{\mathrm{o}}$, and is longer for a higher $\mathrm{V}_{\mathrm{o}}$. Note that the start-up circuit has to be disconnected from the control loop in the steady state, so as not to influence the proper control of the converter.

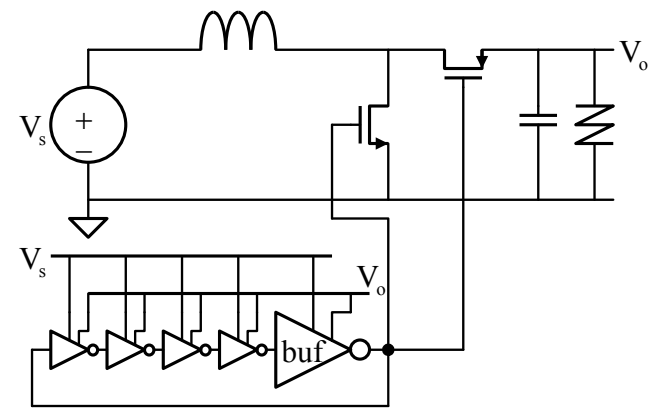

Figure 3: TVS start-up scheme

The proposed start-up scheme is shown in Fig. 3. It also uses a 5-stage ring oscillator to achieve spontaneous oscillation and generate the $50 \%$ duty cycle clock. However, the inverters and inverting buffer are driven by both the input supply voltage $V_{s}$ and the output voltage of the converter $V_{0}$, called dual-supply inverter (NOT_D) as shown in Fig. 4.
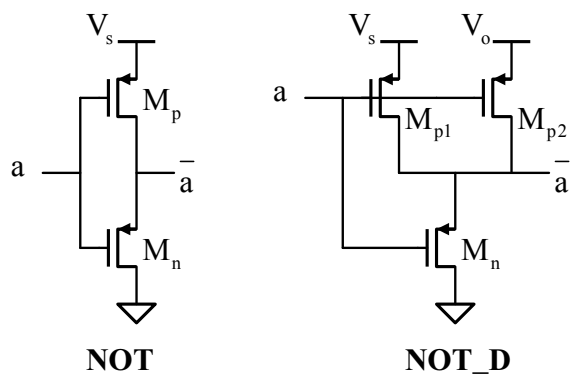

Fig. 4 Conventional and dual-supply inverter

For a conventional inverter NOT, the output swing is between $V_{s}$ and Gnd. For the dual-supply inverter NOT_D, the output swing depends on the magnitudes of $\mathrm{V}_{\mathrm{s}}$ and $\mathrm{V}_{\mathrm{o}}$. Assume the input to the inverter ' $\mathrm{a}$ ' is low ('0') such that $\mathrm{M}_{\mathrm{n}}$ is off, with $\mathrm{r}_{\mathrm{p} 1}$ and $\mathrm{r}_{\mathrm{p} 2}$ the onresistance of $M_{p 1}$ and $M_{p 2}$ respectively, the high output voltage $\mathrm{V}_{\mathrm{oH}}$ can be computed

$$
\frac{\mathrm{V}_{2}-\mathrm{V}_{\mathrm{oH}}}{\mathrm{r}_{\mathrm{p} 2}}=\frac{\mathrm{V}_{\mathrm{oH}}-\mathrm{V}_{1}}{\mathrm{r}_{\mathrm{p} 1}}
$$

$$
\mathrm{V}_{\mathrm{oH}}=\frac{\mathrm{r}_{\mathrm{p} 1} \mathrm{~V}_{1}+\mathrm{r}_{\mathrm{p} 2} \mathrm{~V}_{2}}{\mathrm{r}_{\mathrm{p}_{1}}+\mathrm{r}_{\mathrm{p} 2}}
$$

Thus, $\mathrm{V}_{\mathrm{oH}}$ is sandwiched between $\mathrm{V}_{\mathrm{s}}$ and $\mathrm{V}_{\mathrm{o}}$. Next, assume $V_{o}>V_{s}$, the voltage swing of $V_{\text {out }}$ of the ring oscillator is then between $\left(\mathrm{r}_{\mathrm{p} 1} \mathrm{~V}_{1}+\mathrm{r}_{\mathrm{p} 2} \mathrm{~V}_{2}\right) /\left(\mathrm{r}_{\mathrm{p} 1}+\mathrm{r}_{\mathrm{p} 2}\right)$ and Gnd, which is higher than that of the conventional inverter. On using the dual-supply ring oscillator, the converter could be started up with the average threshold voltage $\mathrm{V}_{\text {th(ave) }}=\left(\mathrm{V}_{\mathrm{tn}}+\left|\mathrm{V}_{\text {tp }}\right|\right) / 2$, and we denote this scheme as Threshold Voltage Start-up (TVS) scheme. The unregulated output voltage obtained is $1.85 \mathrm{~V}_{\text {th(ave). }}$ The process we used is a $0.35 \mu \mathrm{m}$ process, with $\mathrm{V}_{\text {tn }}=0.59 \mathrm{~V},\left|\mathrm{~V}_{\text {tp }}\right|=0.7 \mathrm{~V}$. Hence, $\mathrm{V}_{\text {th(ave) }}$ (and so is $\left.\mathrm{V}_{\mathrm{st}(\min )}\right)=0.65 \mathrm{~V}$. When the supply voltage $\mathrm{V}_{\mathrm{s}}$ is equal to $V_{\text {th(ave), }}$, the start-up circuitry is activated and powered by both the input voltage $\mathrm{V}_{\mathrm{s}}$ and the output voltage $V_{o}$. The built-in positive feedback mechanism helps boosting the output voltage up, such that $\mathrm{V}_{\text {th(ave) }}$ is good enough for the start-up process. During startup, $\mathrm{V}_{\mathrm{o}}$ is unregulated, but when $\mathrm{V}_{\mathrm{o}}$ reaches $1.85 \mathrm{~V}_{\text {th(ave) }}$ $=1.2 \mathrm{~V}$, the control will be handed over to the steady state controller to regulate the output voltage to the desired value. The start-up circuitry is only $2 \%$ of the power transistors. The switching frequency of the ring oscillator is in the order of MHz. The results are summarized in Table 1.

Table 1: Conventional start-up scheme vs TVS scheme

\begin{tabular}{|l|l|l|}
\hline & $\begin{array}{l}\text { Minimum start-up } \\
\text { input voltage } \mathrm{V}_{\text {st(min) }}\end{array}$ & $\mathrm{V}_{\mathrm{o}}$ with $\mathrm{V}_{\text {st(min) }}$ only \\
\hline$[6]$ & $1.18 \mathrm{~V}_{\text {th(ave) }}$ & $1.2 \mathrm{~V}_{\text {st(min) }}$ \\
\hline TVS & $\mathrm{V}_{\text {th(ave) }}$ & $1.85 \mathrm{~V}_{\text {st(min) }}$ \\
\hline
\end{tabular}

\section{Control Scheme of TVS Boost Converter}

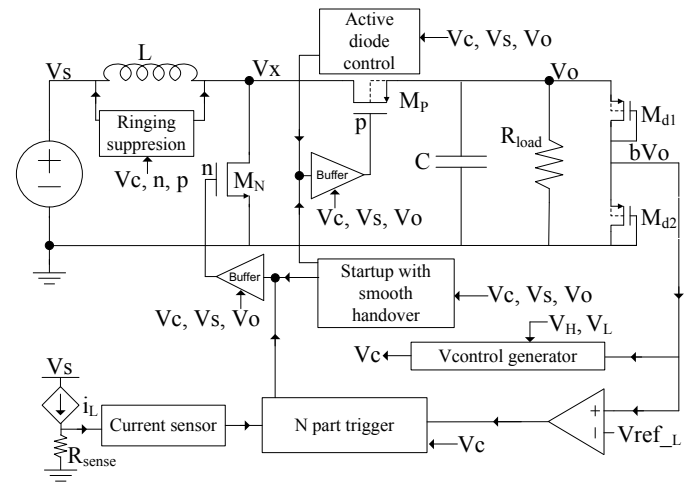

Fig. 5 Block diagram TVS boost converter

The complete control scheme of the TVS boost converter is shown in Fig. 5 and the various operation modes of the converter are shown in Fig. 6. The startup scenario, under light load and heavy load condition in the steady state with peak current control, and start-up after shutdown are all shown. 


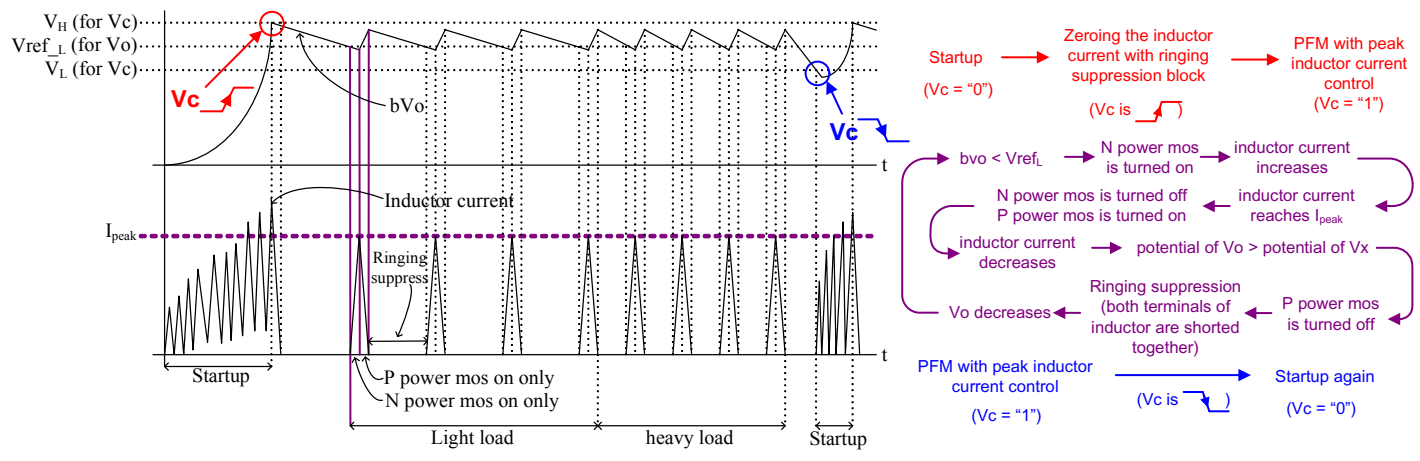

Fig. 6 Output voltage and inductor current of TVS under different operation modes

During start-up, $\mathrm{V}_{\mathrm{o}}$ increases faster and faster, and when $\mathrm{V}_{\mathrm{o}}$ reaches the high voltage limit $\mathrm{V}_{\mathrm{H}}$, the startup process stops, and the $\mathrm{V}$-control generator sets the control signal $\mathrm{V}_{\mathrm{c}}=" 1 "$ and the converter enters the handover mode to avoid $\mathrm{V}_{\mathrm{o}}$ from overshooting. After the short period of handover, the converter operates with peak current control in DCM, and as such, the switching frequency depends on the load, and the converter is considered to operate in PFM (pulse frequency mode) control.

The PFM controller can be separated into two parts. The power transistor $\mathrm{M}_{\mathrm{N}}$ is controlled by the $\mathrm{N}$ Trigger, Current Sensor and Comparator, and the power transistor $\mathrm{M}_{\mathrm{P}}$ is controlled by the Active Diode Control. When $\mathrm{V}_{\mathrm{o}}$ drops and $\mathrm{bV}_{\mathrm{o}}$ drops below $\mathrm{V}_{\text {ref_L }}$, $\mathrm{M}_{\mathrm{N}}$ is turned on and the inductor current $\mathrm{I}_{\mathrm{L}}$ ramps up. When $I_{L}$ reaches $I_{\text {peak }}, M_{N}$ is turned off, and $I_{L}$ charges up the $V_{x}$ node and $M_{P}$ is turned on by the Active Diode Control block, and $\mathrm{I}_{\mathrm{L}}$ charges up $\mathrm{V}_{\mathrm{o}}$ through $\mathrm{M}_{\mathrm{P}}$. The inductor current ramps down, and when it drops to zero, $M_{\mathrm{P}}$ is turned off by the Active Diode Control block. With both $\mathrm{M}_{\mathrm{P}}$ and $\mathrm{M}_{\mathrm{N}}$ are turned off, the converter then enters the free-wheeling mode. The ringing suppression transistors $\mathrm{M}_{\mathrm{ip}}$ and $\mathrm{M}_{\mathrm{in}}$ are turned on by the ringing suppression block until the next cycle begins.

Fig. 6 shows that when the load increases, the switching frequency of the converter also increases. If $\mathrm{V}_{\mathrm{o}}$ drops below $\mathrm{V}_{\mathrm{L}}$ suddenly, the converter changes from the PFM mode to the start-up mode directly to charge up $\mathrm{V}_{\mathrm{o}}$, followed by the handover process and eventually return to the PFM mode. As the converter operates in the PFM mode, a variant of band-band control, no compensation network is needed.

\section{Circuit Implementation}

Logic components: Logic circuits used in the TVS converter have to work in both start-up and PFM mode and are of dual-supply design. Each logic block is disabled with the control signal $\mathrm{V}_{\mathrm{c}}$ differently so that they are powered up by $\mathrm{V}_{\mathrm{o}}$ only after starting up.

V-control generator: It determines when the start-up process is finished and issues the signal $\mathrm{V}_{\mathrm{c}}=" 1$ " to shut off the start-up circuitry and puts the converter in the PFM control mode. To avoid glittering, a voltage hysteresis with a high and low threshold voltage is introduced.

Current sensor: It employs $\mathrm{W} / \mathrm{L}$ ratio matching of $\mathrm{M}_{\mathrm{N}}$ and uses a simple common gate amplifier with a constant bias current. A large peak inductor current causes a large conduction loss by $\mathrm{M}_{\mathrm{N}}$ at the peak current and hurts the efficiency. Therefore, the best is to set the maximum peak inductor current such that at the minimum input voltage with the maximum load current, the converter is operating at the boundary between CCM and DCM. Finally, the peak inductor current is set to around $42 \mathrm{~mA}$.

Active diode control: The active diode is modified from [7]. It compares $V_{x}$ and $V_{o}$ using a common gate amplifier and turns off $\mathrm{M}_{\mathrm{P}}$ to avoid reversion current.

Voltage divider: The minimum current of the converter is designed to be $100 \mu \mathrm{A}$, and if the loss due to the resistor string is $1 \%$, then the resistors have to be in the order of $1 \mathrm{M} \Omega$, which will take up too much silicon area. Here, we set $b=0.5$ and we use two transistors in series to get the required voltage division. The output voltage $\mathrm{V}_{\mathrm{o}}$ is designed to be $1.2 \mathrm{~V}$, which is smaller than $2 \times\left|V_{\text {tp }}\right|$, hence the two PMOS transistors $\mathrm{M}_{\mathrm{d} 1}$ and $\mathrm{M}_{\mathrm{d} 2}$ are working in the subthreshold region.

\section{Measurement}

To demonstrate the proposed start-up scheme, a test chip was fabricated using $0.35 \mu \mathrm{m}$ CMOS process, the performance of threshold voltage start-up and low voltage input are the same as the simulated results. However, the maximum efficiency is reduced by $3 \%$ comparing with the simulation, which may be due to the unexpected noise occurred in the inductor current that increases the true r.m.s. (root-meansquare) of the input current. The overall converter performance is summarized in Table 2. 
Table 2: Chip performance summary

\begin{tabular}{|l|l|}
\hline Technology & $0.35 \mu \mathrm{m}$ CMOS process \\
\hline Inductor / Capacitor & $4.7 \mu \mathrm{H} / 500 \mathrm{nF}$ \\
\hline Switching frequency & $7 \mathrm{MHz}($ startup) \\
& $700 \mathrm{kHz}-15 \mathrm{kHz}(\mathrm{PFM})$ \\
\hline Input supply voltage & $0.15 \mathrm{~V}-0.9 \mathrm{~V}$ \\
\hline Output voltage & $1.2 \mathrm{~V}$ \\
\hline Output ripple voltage & $<24 \mathrm{mV}$ \\
\hline Load current & $0.1 \mathrm{~mA}-1 \mathrm{~mA}$ \\
\hline Efficiency & $\mathrm{Max} .83 \%$ \\
\hline Line regulation & $12.4 \mathrm{mV} / \mathrm{V}$ \\
\hline Load regulation & $19.8 \mathrm{mV} / \mathrm{mA}$ \\
\hline
\end{tabular}

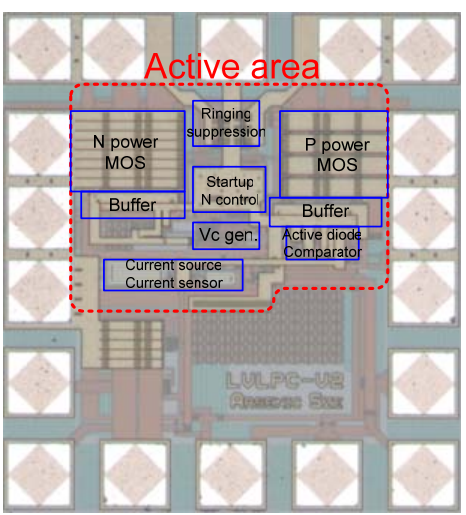

Fig. 7 Die photo of tested chip

Fig. 7 shows the die photo of the TVS boost converter. It measures $675 \mu \mathrm{m} \times 615 \mu \mathrm{m}$. Fig. 8 shows the start-up response of the converter with $\mathrm{V}_{\mathrm{s}}=0.65 \mathrm{~V}$, which is midway between $\mathrm{V}_{\mathrm{tn}}$ and $\left|\mathrm{V}_{\mathrm{tp}}\right|$.

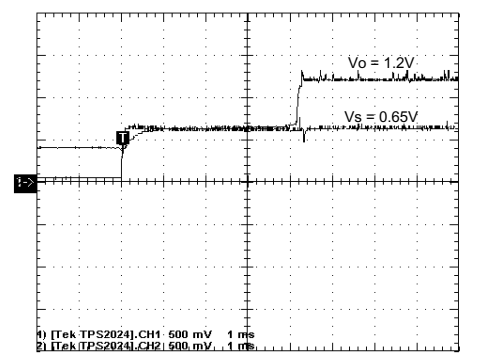

Fig. 8 Start-up response of TVS converter

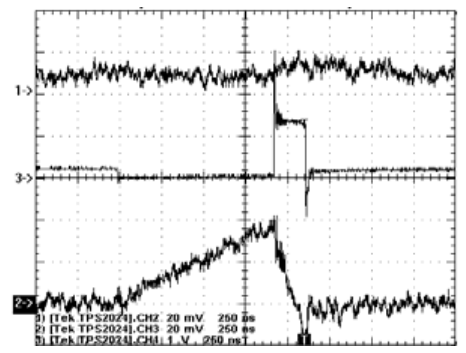

Ch 1: $\mathrm{V}_{\mathrm{o}}$ (AC coupling); Ch 2: Inductor current; Ch 3: $\mathrm{V}_{\mathrm{x}}$

Fig. 9 Min. supply voltage with max. loading current

Fig. 9 shows the steady state response of the converter with minimum supply voltage $(0.2 \mathrm{~V})$ and maximum current loading $(1 \mathrm{~mA})$. The inductor current is too small to be measured by current probe and it is measured by the voltage drop across a $1 \Omega$ resistor in series using TPS 2024 instead. The converter is operating in good DCM mode as shown by the trace of $\mathrm{V}_{\mathrm{x}}$ : when the inductor current is zero, $\mathrm{V}_{\mathrm{x}}$ is equal to $\mathrm{V}_{\mathrm{s}}$ rather than ringing.

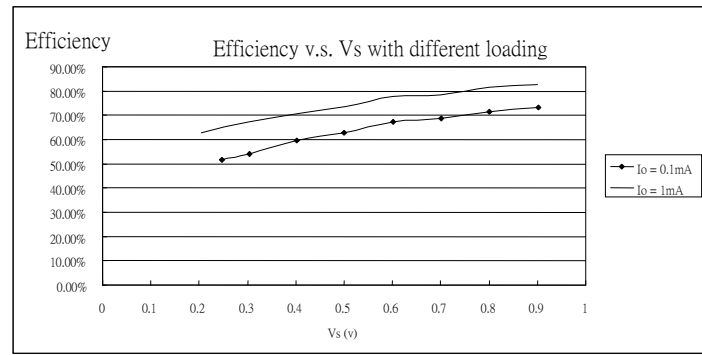

Fig. 10 Measured efficiency vs $V_{s}$ and $I_{o}$

The converter operates in PFM, and when the input supply voltage is very low $(200 \mathrm{mV})$ and the load current is very high $(1 \mathrm{~mA})$, the converter switches faster, and the maximum switching frequency occurs at the boundary of CCM and DCM. The highest and lowest switching frequency is $700 \mathrm{kHz}$ and $15 \mathrm{kHz}$ respectively. The maximum output ripple voltage is $24 \mathrm{mV}$, which is $2 \%$ of $\mathrm{V}_{\mathrm{o}}$. The maximum efficiency is $83 \%$ (Fig. 10).

\section{Conclusion}

A boost converter that could start-up at the average threshold voltage is designed, fabricated and tested. It could operate at $\mathrm{V}_{\mathrm{s}}$ from $0.2 \mathrm{~V}$ to $0.9 \mathrm{~V}$. Moreover, the maximum efficiency is up to $83 \%$ at $1 \mathrm{~mA}$ output current and $0.9 \mathrm{~V}$ input voltage.

\section{References}

[1] Y. H. La B. H. Calhoun et. al., "Design considerations for ultra-low energy wireless microsensor nodes", IEEE Trans. on Computers, pp. 727-740, Jun 2005.

[2] B. A. Warneke, "Ultra-low energy architectures and circuits for cubic millimeter distributed wireless sensor networks", PhD Thesis, UC Berkeley, 2003.

[3] R. Amirtharajah and A. Chandrakasan, "Self-powered signal processing using vibration-based power generation", IEEE J. of Solid-State Circuits, pp.687695, May 1998.

[4] J.A. Von Arx and K. Najafi, "A wireless single-chip telemetry powered neural stimulation system," IEEE Int'l Solid-State Ckts. Conf., pp.214-215, 1999.

[5] R. Amirtharajah et. al., "Circuits for energy harvesting sensor signal processing", ACM/IEEE Design Automation Conf., pp. 639-644, July 2006.

[6] C. Y. Leung, P. Mok and K. N. Leung, "A 1-V integrated current-mode boost converter in standard 3.3/5-V CMOS technologies", IEEE J. of Solid-State Circuits, pp. 2265-2274, Nov. 2005.

[7] Y. H. Lam, W. H. Ki and C. Y. Tsui, "An integrated $1.8 \mathrm{~V}$ to $3.3 \mathrm{~V}$ regulated voltage doubler using active diodes and dual-loop voltage follower for switchcapacitive load", IEEE Symp. on VLSI Circuits, pp. 85-86, 2006. 